\title{
Consórcio sorgo-soja. XVI. Cortes, épocas de semeadura e cultivares de soja na produção de forragem ${ }^{1}$
}

\author{
Sorghum-soybean intercropping. XVI. Cutting systems, sowing date and cultivars of \\ soybean in the forage production
}

\author{
Helio Peres Alcantara ${ }^{2 *}$, Pedro Milanez de Rezende ${ }^{3}$, Everson Reis Carvalho ${ }^{4}$, Alexandre Martins Abdão dos \\ Passos $^{5}$ e Elbéris Pereira Botrel ${ }^{3}$
}

\begin{abstract}
Resumo - O objetivo do presente trabalho foi avaliar o rendimento forrageiro em função de épocas de semeadura, cultivares de soja e sistemas de cortes no sistema consorciado sorgo-soja na entrelinha. Os experimentos foram conduzidos em Lavras-MG, nos anos agrícolas 2006/07 e 2007/08, no Departamento de Agricultura da UFLA, utilizando o delineamento em blocos casualizados em esquema fatorial $5 \times 3 \times 3$, compreendendo cinco épocas de semeadura sorgo-soja, três cultivares de soja e três sistemas de corte. Para efeito de comparação com o sistema consorciado, utilizou-se o monocultivo do sorgo semeado nas cinco épocas. As épocas de semeadura alteraram significativamente o rendimento forrageiro e o teor de proteína bruta do material consorciado, observando-se rendimentos crescentes dessas características com a precocidade da semeadura. As cultivares de soja não alteraram o rendimento forrageiro do consórcio. O sistema de corte 1 (rente ao solo) proporcionou os maiores rendimentos de massa verde, matéria seca e proteína bruta dos materiais consorciados. O sistema de consórcio sorgo-soja proporcionou maior rendimento de massa verde, matéria seca e proteína bruta, comparado ao monocultivo de sorgo.
\end{abstract}

Palavras-chave - Rendimento forrageiro. Sorghum bicolor. Glycine max.

\begin{abstract}
This work aimed to evaluate the forage yield as a result of sowing dates, cultivars of soybean and cutting systems in a sorghum-soybean intercropping system. The experiments were carried out in Lavras-MG, in the agricultural years 2006/07 and 2007/08, in the Department of Agriculture of the UFLA. Were used a randomized complete blocks design in a $5 \times 3 \times 3$ factorial scheme, being five sowing dates sorghum-soybean, three soybean cultivars and three cutting systems. Was used the sorghum monoculture, sown in five sowing dates, in order to compare it to the intercropping system. The sowing dates significantly changed the forage yield and crude protein content of the material intercropping, observing increasing returns to these characteristics with the early sowing. The soybean cultivars did not affect the forage yield of the intercropping. The cutting system 1 (near the soil surface) showed the highest yields of green mass, dry matter and crude protein of the material intercropping. The system of intercropping sorghum-soybean highest yield of green mass, dry matter and crude protein, compared to the monoculture of sorghum.
\end{abstract}

Key words - Forage yield. Sorghum bicolor. Glycine max.

\footnotetext{
* Autor para correspondência

Recebido para publicação em 06/08/2009; aprovado em 03/12/2010

Parte da Dissertação de Mestrado apresentada pelo primeiro autor a Universidade Federal de Lavras para a obtenção do título de Mestre em Agronomia/Fitotecnia, pesquisa financiada pela FAPEMIG

${ }^{2}$ Programa de Pós-Graduação em Agronomia/Fitotecnia da Universidade Federal de Lavras, hphelioperes@yahoo.com.br 3Departamento de Agricultura, DAG/UFLA,pmrezend@ufla.br, elberis@dag.ufla.br

${ }^{4}$ Programa de Pós-Graduação em Agronomia/Fitotecnia da Universidade Federal de Lavras, eversonufla@yahoo.com.br

${ }^{5}$ Pesquisador University of Guelph, Canadá, apassos@uoguelph.ca
} 


\section{Introdução}

O consórcio de plantas forrageiras é uma técnica realizada a alguns anos e consiste na prática de cultivo de duas ou mais culturas na mesma área visando aumentar a produtividade e a qualidade do produto obtido. Em regiões onde há uma intensa atividade da pecuária leiteira, como é o caso da região do Sul de Minas Gerais, o consórcio milho (Zea mays) - soja (Glycine max) é uma das mais utilizadas pois a presença da gramínea é marcante.

No entanto, o milho tem a sua produção e valor nutritivo variando muito de um ano para outro, por ser uma cultura muito sensível à disponibilidade de água no solo (PINHO et al., 2007) e pouco estudada para fins de ensilagem em condições de safrinha (GUARESCHI et al., 2008). Por outro lado, a utilização do sorgo como silagem, que ainda é incipiente, tem se apresentado como uma boa alternativa principalmente em regiões onde ocorrem períodos de estiagem, que normalmente limitam a produção do milho (RODRIGUES FILHO et al., 2006).

A soja, por outro lado, quando utilizada individualmente em forma de feno demonstra ser ótima fonte de minerais (GRIS et al., 2008). Por isso, pesquisas visando a utilização da soja, na ensilagem junto com o sorgo, têm sido realizadas visando se determinar cultivares e técnicas de manejo mais apropriadas para se obter maior rendimento. Diversos autores têm evidenciado o comportamento diferencial de cultivares de soja, altura de corte e épocas de semeadura, quanto ao rendimento e qualidade do feno obtido (BOTREL; REZENDE, 1999; REZENDE et al.,1997; SANTOS et al., 2009).

Santos et al. (2009), em pesquisa envolvendo consórcio entre sorgo com soja na entrelinha, observaram maiores rendimentos forrageiros e melhor qualidade nutricional do consórcio em relação ao monocultivo. Esses mesmos autores verificaram ainda que o sistema de corte a $15 \mathrm{~cm}$ do colo da planta proporcionou os maiores rendimento forrageiro.

Nesse contexto, existem alguns relatos mostrando a vantagem do consórcio sobre o monocultivo comparando o rendimento de grãos ou de forragem visando constatar a viabilidade desse sistema (BEZERRA et al, 2007; EVANGELISTA et al., 2005; GHOSH et al., 2009; REZENDE et al., 2004). Além disso, sistemas de manejo convencionais (monocultura) favorecem mais os processos de erosão, tendo perdido espaço através da adoção de manejos mais conservacionistas adotados com o intuito de minimizar os prejuízos ao meio ambiente por promoverem uma melhor cobertura vegetal da área (AZEVEDO et al. 2007).
Objetivou-se com o presente trabalho avaliar o desempenho médio, em dois anos agrícolas, em diferentes épocas de semeadura, de cultivares de soja e sistemas de corte no rendimento forrageiro do consórcio sorgo-soja na entrelinha e em monocultivo.

\section{Material e métodos}

O ensaio foi conduzido no Campus da Universidade Federal de Lavras, em Lavras, MG, a uma altitude de 918 metros, em soloclassificado comoLatossolo Roxo distroférrico típico de textura argilosa, fase cerrado, cujas características foram às seguintes: $\mathrm{pH}$ em água 5,4 (Acidez média); $\mathrm{Al}^{+++}$ trocável =0,1 $\mathrm{cmol}_{\mathrm{c}} \mathrm{dm}^{-3}$ (Baixo); $\mathrm{Ca}^{++}=2,9 \mathrm{cmol}_{\mathrm{c}} \mathrm{dm}^{-3}$ (Bom); $\mathrm{Mg}^{++}=0,8^{\mathrm{c}} \mathrm{cmol}_{\mathrm{c}} \mathrm{dm}^{-3}$ (Médio); $\mathrm{P}=13 \mathrm{mg} \mathrm{dm}^{-3}$ (Bom); $\mathrm{K}^{+}=59 \mathrm{mg} \mathrm{dm}{ }^{-3}$ (Médio), interpretações de acordo com Ribeiro et al. (1999). A precipitação pluviométrica e temperatura média observadas durante os anos agrícolas 2006/07 e 2007/08 são apresentadas na Figura 1.

$\mathrm{O}$ delineamento experimental utilizado para $\mathrm{o}$ consórcio foi delineamento em blocos casualizados com esquema fatorial $5 \times 3 \times 3$, com três repetições, compreendendo cinco épocas de semeadura do sorgosoja (30/out, $15 /$ nov, 30/nov, $15 / \mathrm{dez}$ e $30 / \mathrm{dez}$ ), três cultivares de soja (Monsoy 8400 de ciclo médio, Conquista de ciclo semitardio e Luziânia de ciclo tardio); e três sistemas de corte (colheita) realizados no estádio de grãos farináceos do sorgo (no primeiro sistema, as plantas de sorgo e soja foram cortadas rentes ao solo e, no segundo sistema as plantas foram cortadas a uma altura de $15 \mathrm{~cm}$ do colo da planta, no terceiro sistema as plantas foram cortadas a $30 \mathrm{~cm}$ do colo da planta). O cultivo do sorgo em monocultivo foi avaliado por outro ensaio contíguo em blocos casualizados, semeado nas cinco épocas supracitadas, para efeito de comparação com o sistema consorciado.

O sistema de cultivo empregado para o consórcio foi o do plantio da soja na entrelinha do sorgo adotandose o espaçamento para o mesmo de $80 \mathrm{~cm}$ e densidade de 12 plantas por metro tanto no consórcio como no monocultivo, definidos em trabalho anterior como os mais promissores para o sistema. No monocultivo da soja e sorgo foram realizadas operações convencionais sendo os cortes realizados uma única vez, rente ao solo, obedecendo às épocas apropriadas de cada cultura $\left(\mathrm{R}_{5}\right.$ para a soja e grãos farináceos para o sorgo). No caso da soja nesse sistema foi utilizado o espaçamento de $50 \mathrm{~cm}$ e densidade de 15 plantas e no consórcio também.

Os experimentos foram instalados nos anos agrícolas de 2006/07 e 2007/08, com semeadura simultânea das duas culturas, nas épocas já relatadas anteriormente. As parcelas 


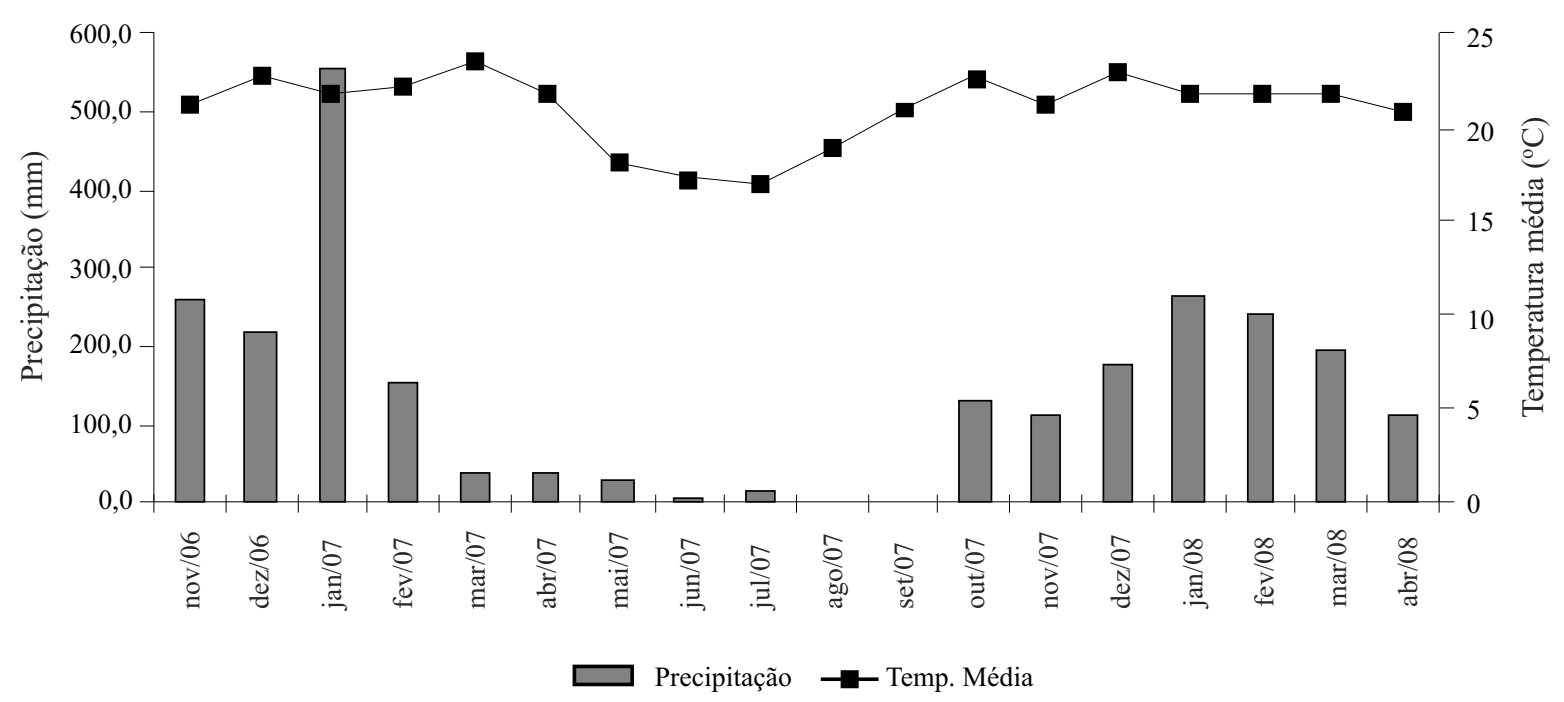

Figura 1 - Precipitação pluvial e temperatura média, ano agrícola 2006/2007 e 2007/2008, obtidas junto à Estação Climatológica Principal de Lavras, MG, UFLA

de sorgo foram constituídas por três linhas com 10,0 m de comprimento, sendo considerada como área útil apenas a fileira central, utilizando o híbrido de sorgo Volumax, para a soja utilizou uma linha central como área útil. $\mathrm{O}$ desbaste foi realizado aos 25 dias após a emergência, para o sorgo e soja deixando-se as densidades relatadas anteriormente, tanto em monocultivo como em consórcio.

Para as duas culturas, as adubações foram recomendadas de acordo com Ribeiro et al. (1999), utilizando-se para a soja $120 \mathrm{~kg} \mathrm{ha}^{-1} \mathrm{de}_{2} \mathrm{O}_{5}$ e $120 \mathrm{~kg} \mathrm{ha}^{-1}$ de $\mathrm{K}_{2} \mathrm{O}$ e para o sorgo $20 \mathrm{~kg} \mathrm{ha}^{-1}$ de $\mathrm{N}, 80 \mathrm{~kg} \mathrm{ha}^{-1}$ de $\mathrm{P}_{2} \mathrm{O}_{5}$ e $50 \mathrm{~kg} \mathrm{ha}^{-1}$ de $\mathrm{K}_{2} \mathrm{O} \mathrm{kg} \mathrm{ha}^{-1}$ no plantio e $40 \mathrm{~kg} \mathrm{ha}^{-1} \mathrm{de} \mathrm{N}$ em cobertura aos 30 e 45 dias após a emergência das plantas. Utilizaram-se, como fonte de $\mathrm{N}$ de $\mathrm{P}_{2} \mathrm{O}_{5}$ e de $\mathrm{K}_{2} \mathrm{O}$, o sulfato de amônio, o supersimples e o cloreto de potássio, respectivamente. Antes da semeadura, foi realizada a inoculação das sementes de soja com Bradyrhizobium japonicum, utilizando 1.200 .000 bactérias/semente. Os demais tratos culturais foram realizados conforme necessidade das culturas envolvidas. O corte das plantas de sorgo foi realizado nas épocas já relatadas anteriormente, com roçadora costal motorizada.

Por ocasião dos cortes, foram avaliadas separadamente, para a cultura do sorgo e da soja, as características descritas a seguir:

Massa verde: todas as plantas de sorgo da parcela útil foram cortadas de acordo com o sistema de corte e pesadas em uma balança com carga máxima de $50 \mathrm{~kg}$ e precisão de $50 \mathrm{~g}$. Posteriormente, o peso resultante foi convertido para $\mathrm{kg} \mathrm{ha}^{-1}$.
Matéria seca: Posteriormente à pesagem de todas as plantas da fileira útil, foram retiradas amostras de 10 plantas por parcela, que foram trituradas, usando picador de forragem, e homogeneizadas. Deste material, foi retirada uma subamostra de $300 \mathrm{~g}$ para a determinação da matéria seca, que foi realizada, por meio da secagem do material, utilizando-se, estufa de circulação forçada de ar à temperatura de $65{ }^{\circ} \mathrm{C}$ até atingir peso constante. Após determinado o valor da matéria seca, foi feita a conversão para $\mathrm{kg} \mathrm{ha}^{-1}$.

Proteína bruta: a determinação do rendimento de proteína bruta foi realizada a partir o material retirado para a determinação da matéria seca. Para isso, após a pesagem, o material foi moído em um moinho tipo Willey e peneirado com auxilio de peneiras de 1,0 $\mathrm{mm}$ de bitola, e em seguida guardado em recipientes de vidro devidamente identificados. Posteriormente enviaram-se amostras ao Laboratório de Análise Foliar da UFLA, onde foi determinado o teor de nitrogênio, utilizando-se o aparelho de destilação a vapor microKjeldahl, de acordo com técnicas da AOAC (1990) e os resultados convertidos para $\mathrm{kg} \mathrm{ha}^{-1}$.

As análises estatísticas foram realizadas utilizando-se o Software Sistema de Análise de Variância (SISVARß) (FERREIRA, 2008), para as características citadas anteriormente para a cultura do sorgo, de acordo com o esquema de análise de variância adaptada de Yassin et al. (2002). As médias, quando significativas pelo teste $\mathrm{F}$, foram comparadas por meio do teste de Scott-Knott, a 5\% de probabilidade. 


\section{Resultados e discussão}

\section{Rendimento de massa verde total}

De acordo com a análise de variância para o rendimento de massa verde do consórcio verifica-se que as épocas de semeadura, sistemas de corte e a interação época $\mathrm{x}$ sistema de corte alteraram significativamente $\mathrm{o}$ seu desempenho (TAB. 1).

O rendimento de massa verde do consórcio foi influenciado significativamente pelas épocas de semeadura, podendo-se observar que o rendimento caiu à medida que se atrasou a semeadura (TAB. 2). De acordo com a Tabela 2 verifica-se que as épocas de semeadura 30/out e 15/nov destacaram-se, sendo que a primeira época proporcionou rendimento de $44.020 \mathrm{~kg} \mathrm{ha}^{-1}$ superando as épocas 30/nov, 15 e 30/dez em 9.477; 14.072; $25.313 \mathrm{~kg} \mathrm{ha}^{-1}$, respectivamente. O rendimento obtido na semeadura realizada em $15 /$ nov foi de $43.380 \mathrm{~kg} \mathrm{ha}^{-1}$, proporcionou acréscimos em relação às épocas 30/nov, $15 \mathrm{e}$ $30 /$ dez de $8.837 ; 13.432 ; 24.673 \mathrm{~kg} \mathrm{ha}^{-1}$, respectivamente.

De acordo com a Tabela 2 podemos observar rendimentos decrescentes de massa verde com o avanço da época de semeadura, sendo verificado o mais baixo rendimento na última época 30/12. Esses resultados indicam que essa característica encontra- se intimamente relacionada com o desenvolvimento vegetativo da mesma. Nas épocas mais tardias de semeadura as plantas estiveram sob um regime pluviométrico com menor disponibilidade hídrica (FIG. 1) se comparadas às semeaduras realizadas anteriormente, o que leva essas culturas a diminuírem o desenvolvimento vegetativo e consequentemente seus rendimentos. Resultados coincidentes a esses foram verificados por Barros et al. (2003), que estudaram o efeito dessa característica e também constataram decréscimos com o retardamento da semeadura.

Quanto aos sistemas de corte houve maior rendimento de massa verde para o corte realizado rente ao solo (sistema de corte 1), com uma produção de 38.324 $\mathrm{kg} \mathrm{ha}^{-1}$ superando os sistemas 2 e 3 . Fato este resultado das alturas de cortes realizadas nos sistemas, visto que nos sistema 2 e 3 as alturas de cortes foram 15 e 30 $\mathrm{cm}$, respectivamente, ao passo que no sistema 1 o corte foi efetuado rente ao solo, proporcionado assim maior rendimento de massa verde.

Com relação à interação época $\mathrm{x}$ sistema de corte, fazendo o desdobramento do fator época dentro dos sistemas de corte pode-se observar que, para o sistema 1 a melhor época de semeadura foi $15 /$ nov, enquanto que para os demais cortes a melhor época de semeadura foi a realizada em 30/out.

Tabela 1 - Resumo da análise de variância para os rendimentos médios de massa verde, matéria seca e proteína bruta $\left(\mathrm{kg} \mathrm{ha}^{-1}\right)$ obtidos do consórcio das culturas de sorgo e soja, em função de épocas de semeadura do sorgo, cultivares de soja e de sistemas de cortes. UFLA, Lavras/MG, anos agrícolas 2006/07 e 2007/08

\begin{tabular}{ccccc}
\hline \multirow{2}{*}{ Fonte de Variação } & GL & \multicolumn{3}{c}{ Quadrados médios } \\
\cline { 2 - 4 } Blocos & 2 & Massa verde & Matéria seca & Proteína Bruta \\
\hline (Tratamentos) & 49 & $768323247^{* *}$ & 4507024 & 13693 \\
Consórcio & $323065243^{* *}$ & $36478768^{* *}$ & $284579^{* *}$ \\
Época (E) & 4 & & $2145009 * *$ \\
Cultivar (C) & 2 & $2962519260^{* *}$ & $257924481^{* *}$ & 36215 \\
Sist. de corte (S) & 2 & 4068546 & 954235 & $433562^{* *}$ \\
E*C & 8 & $601012017^{* *}$ & $120434260^{* *}$ & $80762^{* *}$ \\
E*S & 8 & 20604134 & $6392629 *$ & $120735^{* *}$ \\
C*S & 4 & $55318044 * *$ & $11010160^{* *}$ & 19767 \\
E*C*S & 16 & 24731994 & 4421572 & $52086^{* *}$ \\
Monocultivo & 4 & 26585864 & $5277479 * *$ & $168291^{* *}$ \\
Cons. vs. Monoc. & 1 & $391535416^{* *}$ & $50806397 * *$ & $1227206^{* *}$ \\
Resíduo & 98 & $72137869^{*}$ & $68410867 * *$ & 12592 \\
\hline C.V. (\%) & & 15716442 & 2401909 & 10,86 \\
\hline
\end{tabular}

**, * significativo, pelo teste $\mathrm{F}$, a $1 \%$ e $5 \%$, respectivamente 
Tabela 2 - Resultados médios de rendimentos de massa verde $\left(\mathrm{kg} \mathrm{ha}^{-1}\right)$ do consórcio sorgo-soja, em função das épocas de semeadura, cultivares de soja e sistemas de cortes. UFLA, Lavras/MG, anos agrícolas 2006/07 e 2007/08 *

\begin{tabular}{|c|c|c|c|c|c|}
\hline Época & Cultivar & Sistema $1(0 \mathrm{~cm})$ & Sistema $2(15 \mathrm{~cm})$ & Sistema $3(30 \mathrm{~cm})$ & Média \\
\hline \multirow{3}{*}{$30 / 10$} & $\mathrm{~L}$ & 43.333 & 42.042 & 41.500 & 42.292 \\
\hline & M & 50.317 & 43.125 & 42.833 & 45.425 \\
\hline & $\mathrm{C}$ & 49.825 & 40.500 & 42.708 & 44.344 \\
\hline \multirow{3}{*}{$15 / 11$} & $\mathrm{~L}$ & 48.125 & 46.417 & 38.908 & 44.483 \\
\hline & M & 57.698 & 38.755 & 36.536 & 44.330 \\
\hline & $\mathrm{C}$ & 48.864 & 39.045 & 36.075 & 41.328 \\
\hline \multirow{3}{*}{$30 / 11$} & $\mathrm{~L}$ & 37.995 & 33.597 & 32.957 & 34.849 \\
\hline & M & 36.208 & 33.715 & 31.985 & 33.969 \\
\hline & $\mathrm{C}$ & 41.382 & 34.461 & 28.589 & 34.811 \\
\hline \multirow{3}{*}{$15 / 12$} & $\mathrm{~L}$ & 32.467 & 27.464 & 30.623 & 30.184 \\
\hline & M & 33.018 & 28.379 & 24.333 & 28.577 \\
\hline & $\mathrm{C}$ & 34.093 & 27.701 & 31.459 & 31.084 \\
\hline \multirow{3}{*}{$30 / 12$} & $\mathrm{~L}$ & 24.062 & 19.164 & 17.690 & 20.305 \\
\hline & M & 19.311 & 17.141 & 18.379 & 18.277 \\
\hline & $\mathrm{C}$ & 18.157 & 13.556 & 20.908 & 17.541 \\
\hline \multicolumn{2}{|c|}{ Médias dos Sistemas } & $38.324 \mathrm{a}$ & $32.337 \mathrm{~b}$ & $31.699 \mathrm{~b}$ & \\
\hline \multicolumn{2}{|c|}{$30 / 10$} & $47.825 \mathrm{~B}$ & $41.889 \mathrm{~A}$ & $42.347 \mathrm{~A}$ & $44.020 \mathrm{~A}$ \\
\hline \multicolumn{2}{|c|}{$15 / 11$} & $51.562 \mathrm{~A}$ & $41.405 \mathrm{~A}$ & $37.173 \mathrm{~B}$ & $43.380 \mathrm{~A}$ \\
\hline \multicolumn{2}{|c|}{$30 / 11$} & $38.528 \mathrm{C}$ & $33.924 \mathrm{~B}$ & $31.177 \mathrm{C}$ & $34.543 \mathrm{~B}$ \\
\hline \multicolumn{2}{|c|}{$15 / 12$} & $33.193 \mathrm{D}$ & $27.848 \mathrm{C}$ & $28.805 \mathrm{C}$ & $29.948 \mathrm{C}$ \\
\hline \multicolumn{2}{|c|}{$30 / 12$} & $20.510 \mathrm{E}$ & $16.620 \mathrm{D}$ & $18.992 \mathrm{D}$ & $18.708 \mathrm{D}$ \\
\hline \multicolumn{2}{|c|}{$\mathrm{L}$} & 37.196 & 33.737 & 32.336 & 34.423 \\
\hline \multicolumn{2}{|c|}{ M } & 39.311 & 32.223 & 30.813 & 34.115 \\
\hline \multicolumn{2}{|c|}{$\mathrm{C}$} & 38.464 & 31.053 & 31.948 & 33.822 \\
\hline \multicolumn{2}{|c|}{ Médias do Consórcio } & & & & $34.120 \mathrm{~A}$ \\
\hline \multicolumn{2}{|c|}{ Monocultivo do Sorgo } & & & & $31.808 \mathrm{~B}$ \\
\hline
\end{tabular}

*Médias seguidas pela mesma letra minúscula na linha e maiúscula na coluna não diferem entre si, pelo teste de Scott-Knott, a 5\% de probabilidade

No contraste consórcio vs. monocultivo (TAB. 2), é importante ressaltar que o rendimento médio de massa verde foi incrementado significativamente no consórcio, mostrando que a presença da soja consorciada na entrelinha do sorgo eleva o rendimento de massa verde, o rendimento médio no consórcio foi de $34.120 \mathrm{~kg} \mathrm{ha}^{-1}$ ao passo que no monocultivo $31.808 \mathrm{~kg} \mathrm{ha}^{-1}$. Valores contrastantes aos encontrados por Silva et al. (2000), que não encontraram diferença entre os rendimentos do monocultivo de sorgo e do consórcio sorgo-soja semeados na linha, porém corroboram aos de Corte et al. (2003), Ghosh et al. (2004) e Rezende et al. (2005), que confirmam a vantagem do sistema consorciado na entrelinha em relação ao monocultivo. Esses resultados concordam também com os obtidos por Santos et al. (2009), trabalhando com outro híbrido de sorgo, verificou um rendimento do sistema consorciado superior ao monocultivo do sorgo.

\section{Rendimento de matéria seca}

O resumo da análise de variância para $\mathrm{o}$ rendimento de matéria seca encontra-se na Tabela 1. Pelos resultados da análise dos tratamentos envolvendo o consórcio das duas culturas, observa-se efeito significativo para época de semeadura, sistemas de corte, interação cultivar época de semeadura, para o contraste consórcio versus monocultivo. 
Os sistemas de corte alteraram significativamente o rendimento de matéria seca do consórcio, podendo-se observar que o sistema 1 , com rendimento de $16.184 \mathrm{~kg} \mathrm{ha}^{-1}$, apresentou melhor desempenho em relação aos sistemas de corte 2 e 3 (TAB. 3). Em contrapartida, Pedó et al. (2008), observaram que o aumento na altura de corte das plantas aumentou o percentual de matéria seca, utilizando silagens de milho safrinha.

Avaliando-se o efeito do fator cultivar dentro das épocas de semeadura verifica-se que as cultivares apresentam mesmo comportamento nas diferentes épocas, exceto na semeadura realizada em 30/nov, que a cultivar Conquista superou as demais, conforme indica a Tabela 3. Em relação ao rendimento médio das cinco épocas de semeadura avaliadas (TAB. 3) é importante ressaltar que o maior rendimento de matéria seca foi obtido na época $15 /$ nov com produtividade de 17.358 superando em $1.496 ; 2.135 ; 3.597 ; 8.086 \mathrm{~kg} \mathrm{ha}^{-1}$ as épocas 30/out, 30/nov, 15 e 30/dez, respectivamente.

Estudando o efeito do fator época dentro de cada sistema de corte observa-se na Tabela 3 que para o sistema de corte 1 a semeadura em $15 /$ nov proporcionou maior rendimento ( $\left.21.201 \mathrm{~kg} \mathrm{ha}^{-1}\right)$, enquanto que para os sistemas 2 e 3 essas épocas foram 30/out a 30/nov e 30/out a $15 /$ dez, respectivamente.

Conforme pode ser observado, pelos dados da Tabela 3, o rendimento médio do sorgo no consórcio (14.296 kg ha-1) foi superior ao obtido no monocultivo

Tabela 3 - Valores médios de rendimentos de matéria seca $\left(\mathrm{kg} \mathrm{ha}^{-1}\right)$, do consórcio sorgo-soja, em função das épocas de semeadura, cultivares de soja e sistemas de cortes. UFLA, Lavras/MG, anos agrícolas 2006/07 e 2007/08 *

\begin{tabular}{|c|c|c|c|c|c|}
\hline Época & Cultivar & Sistema $1(0 \mathrm{~cm})$ & Sistema $2(15 \mathrm{~cm})$ & Sistema $3(30 \mathrm{~cm})$ & Média \\
\hline \multirow{3}{*}{$30 / 10$} & $\mathrm{~L}$ & 15.766 & 15.489 & 15.143 & $15.466 \mathrm{~A}$ \\
\hline & M & 18.153 & 15.202 & 14.953 & $16.103 \mathrm{~A}$ \\
\hline & $\mathrm{C}$ & 18.717 & 14.170 & 15.166 & $16.018 \mathrm{~A}$ \\
\hline \multirow{3}{*}{$15 / 11$} & $\mathrm{~L}$ & 20.006 & 17.052 & 14.460 & 17.172 A \\
\hline & M & 24.191 & 15.763 & 14.882 & $18.279 \mathrm{~A}$ \\
\hline & $\mathrm{C}$ & 19.406 & 15.532 & 14.934 & $16.624 \mathrm{~A}$ \\
\hline \multirow{3}{*}{$30 / 11$} & $\mathrm{~L}$ & 14.619 & 13.893 & 13.914 & $14.142 \mathrm{~B}$ \\
\hline & M & 16.064 & 14.895 & 14.328 & $15.095 \mathrm{~B}$ \\
\hline & $\mathrm{C}$ & 19.545 & 15.541 & 14.211 & $16.432 \mathrm{~A}$ \\
\hline \multirow{3}{*}{$15 / 12$} & $\mathrm{~L}$ & 15.337 & 11.812 & 14.083 & $13.744 \mathrm{~A}$ \\
\hline & M & 15.181 & 13.289 & 11.414 & $13.295 \mathrm{~A}$ \\
\hline & $\mathrm{C}$ & 15.375 & 13.067 & 14.296 & $14.246 \mathrm{~A}$ \\
\hline \multirow{3}{*}{$30 / 12$} & $\mathrm{~L}$ & 11.780 & 9.600 & 8.998 & $10.126 \mathrm{~A}$ \\
\hline & M & 9.378 & 8.538 & 9.052 & $8.990 \mathrm{~A}$ \\
\hline & $\mathrm{C}$ & 9.251 & 6.536 & 10.319 & $8.702 \mathrm{~A}$ \\
\hline \multicolumn{2}{|c|}{ Médias dos sistemas } & $16.185 \mathrm{a}$ & $13.359 \mathrm{~b}$ & $13.343 \mathrm{~b}$ & \\
\hline \multicolumn{2}{|c|}{$30 / 10$} & $17.546 \mathrm{~B}$ & $14.954 \mathrm{~A}$ & $15.088 \mathrm{~A}$ & $15.862 \mathrm{~B}$ \\
\hline \multicolumn{2}{|c|}{$15 / 11$} & $21.201 \mathrm{~A}$ & $16.116 \mathrm{~A}$ & $14.758 \mathrm{~A}$ & $17.358 \mathrm{~A}$ \\
\hline \multicolumn{2}{|c|}{$30 / 11$} & $16.742 \mathrm{~B}$ & $14.776 \mathrm{~A}$ & $14.151 \mathrm{~A}$ & $15.223 \mathrm{C}$ \\
\hline \multicolumn{2}{|c|}{$15 / 12$} & $15.298 \mathrm{C}$ & $12.723 \mathrm{~B}$ & $13.264 \mathrm{~A}$ & $13.762 \mathrm{D}$ \\
\hline \multicolumn{2}{|c|}{$30 / 12$} & $10.136 \mathrm{D}$ & $8.225 \mathrm{C}$ & $9.456 \mathrm{E}$ & $9.273 \mathrm{E}$ \\
\hline \multicolumn{2}{|c|}{$\mathrm{L}$} & 15.502 & 13.569 & 13.320 & 14.130 \\
\hline \multicolumn{2}{|c|}{ M } & 16.593 & 13.537 & 12.926 & 14.352 \\
\hline \multicolumn{2}{|c|}{$\mathrm{C}$} & 16.459 & 12.969 & 13.785 & 14.404 \\
\hline \multicolumn{2}{|c|}{ Médias do Consórcio } & & & & $14.296 \mathrm{~A}$ \\
\hline \multicolumn{2}{|c|}{ Monocultivo do Sorgo } & & & & $12.044 \mathrm{~B}$ \\
\hline
\end{tabular}

*Médias seguidas pela mesma letra minúscula na linha e maiúscula na coluna não diferem entre si, pelo teste de Scott-Knott, a 5\% de probabilidade 
(12.044 $\left.\mathrm{kg} \mathrm{ha}^{-1}\right)$, mostrando a eficiência da consorciação, proporcionando aumento na ordem de $18,69 \%(2.252$ $\left.\mathrm{kg} \mathrm{ha}^{-1}\right)$.

Resultados semelhantes foram constatados por Santos et al. (2009) e Corte et al. (2003) que trabalhando com consórcio sorgo-soja na entrelinha, verificaram aumentos nos rendimentos de matéria seca em cultivos consorciados em relação ao monocultivo.

\section{Rendimento de proteína bruta total}

De acordo com o resumo da análise de variância para o rendimento de proteína bruta total, apresentado na Tabela 1, houve diferenças significativas para época de semeadura, sistemas de corte, e para as interações época $\mathrm{x}$ cultivar, época $\mathrm{x}$ sistema de corte e para $\mathrm{o}$ contraste consórcio vs. monocultivo.

Estudando-se o fator cultivar dentro de cada época (TAB. 4), verifica-se que nas épocas de semeadura 30/ out e $15 /$ nov as cultivares apresentaram comportamentos distintos, com destaque para Conquista em 30/out e menor rendimento em 15/nov. Para as outras épocas não foi verificado diferença significativa entre as cultivares.

Em relação à interação época $\mathrm{x}$ sistema de corte significativa, estudando-se o fator épocas de semeadura dentro dos sistemas de cortes (TAB. 4), pode-se observar que para o sistema 1 a melhor época de semeadura visando proteína é $15 /$ nov, para o sistema 2 foi a época $30 / 10$ e para o sistema 3 a época de maior

Tabela 4 - Valores médios de rendimentos de proteína bruta $\left(\mathrm{kg} \mathrm{ha}^{-1}\right)$, do consórcio sorgo-soja, em função das épocas de semeadura, cultivares de soja e de sistemas de cortes. UFLA, Lavras/MG, anos agrícolas 2006/07 e 2007/08 *

\begin{tabular}{|c|c|c|c|c|c|}
\hline Época & Cultivar & Sistema $1(0 \mathrm{~cm})$ & Sistema $2(15 \mathrm{~cm})$ & Sistema $3(30 \mathrm{~cm})$ & Média \\
\hline \multirow{3}{*}{$30 / 10$} & $\mathrm{~L}$ & 1.395 & 1.317 & 1.105 & $1.272 \mathrm{~B}$ \\
\hline & M & 1.078 & 1.275 & 1.041 & $1.132 \mathrm{C}$ \\
\hline & $\mathrm{C}$ & 1.584 & 1.452 & 1.270 & $1.435 \mathrm{~A}$ \\
\hline \multirow{3}{*}{$15 / 11$} & $\mathrm{~L}$ & 1.489 & 1.397 & 1.242 & $1.376 \mathrm{~A}$ \\
\hline & M & 1.805 & 1.155 & 1.024 & $1.328 \mathrm{~A}$ \\
\hline & $\mathrm{C}$ & 1.451 & 1.112 & 920 & $1.161 \mathrm{~B}$ \\
\hline \multirow{3}{*}{$30 / 11$} & $\mathrm{~L}$ & 1.133 & 957 & 1.179 & $1.089 \mathrm{~A}$ \\
\hline & M & 1.124 & 1.136 & 1.170 & $1.143 \mathrm{~A}$ \\
\hline & $\mathrm{C}$ & 1.315 & 1.216 & 964 & $1.165 \mathrm{~A}$ \\
\hline \multirow{3}{*}{$15 / 12$} & $\mathrm{~L}$ & 1.066 & 972 & 1.096 & $1.044 \mathrm{~A}$ \\
\hline & M & 1.131 & 1.010 & 832 & $991 \mathrm{~A}$ \\
\hline & $\mathrm{C}$ & 1.105 & 957 & 990 & $1.017 \mathrm{~A}$ \\
\hline \multirow{3}{*}{$30 / 12$} & $\mathrm{~L}$ & 720 & 607 & 619 & $648 \mathrm{~A}$ \\
\hline & M & 619 & 512 & 567 & $566 \mathrm{~A}$ \\
\hline & $\mathrm{C}$ & 604 & 371 & 793 & $589 \mathrm{~A}$ \\
\hline \multicolumn{2}{|c|}{ Médias dos Sistemas } & $1.175 \mathrm{a}$ & $1.030 \mathrm{~b}$ & $987 \mathrm{~b}$ & \\
\hline \multicolumn{2}{|c|}{$30 / 10$} & $1.353 \mathrm{~B}$ & $1.348 \mathrm{~A}$ & $1.138 \mathrm{~A}$ & $1.280 \mathrm{~A}$ \\
\hline \multicolumn{2}{|c|}{$15 / 11$} & $1.582 \mathrm{~A}$ & $1.221 \mathrm{~B}$ & $1.062 \mathrm{~A}$ & $1.288 \mathrm{~A}$ \\
\hline \multicolumn{2}{|c|}{$30 / 11$} & $1.191 \mathrm{C}$ & $1.103 \mathrm{C}$ & $1.104 \mathrm{~A}$ & $1.133 \mathrm{~B}$ \\
\hline \multicolumn{2}{|c|}{$15 / 12$} & $1.100 \mathrm{C}$ & $979 \mathrm{D}$ & $973 \mathrm{~B}$ & $1.018 \mathrm{C}$ \\
\hline \multicolumn{2}{|c|}{$30 / 12$} & $648 \mathrm{D}$ & $497 \mathrm{E}$ & $660 \mathrm{C}$ & $601 \mathrm{D}$ \\
\hline \multicolumn{2}{|c|}{$\mathrm{L}$} & 1.160 & 1.050 & 1.048 & 1.086 \\
\hline \multicolumn{2}{|c|}{ M } & 1.151 & 1.018 & 927 & 1.032 \\
\hline \multicolumn{2}{|c|}{$\mathrm{C}$} & 1.212 & 1.022 & 987 & 1.074 \\
\hline \multicolumn{2}{|c|}{ Médias do Consórcio } & & & & $1.064 \mathrm{~A}$ \\
\hline \multicolumn{2}{|c|}{ Monocultivo do Sorgo } & & & & $762 \mathrm{~B}$ \\
\hline
\end{tabular}

*Médias seguidas pela mesma letra minúscula na linha e maiúscula na coluna não diferem entre si, pelo teste de Scott-Knott, a 5\% de probabilidade 
rendimentos está compreendida no período entre 30 / out e $30 /$ nov.

Em relação ao sistema de corte empregado, verifica-se que o sistema $1\left(1.175 \mathrm{~kg} \mathrm{ha}^{-1}\right)$ proporcionou o maior rendimento superando o sistema 2 e 3 . Resultados discordantes foram obtidos por Santos et al. (2009) que trabalhando com sistemas semelhantes constataram maiores rendimentos no sistema de corte a altura de $15 \mathrm{~cm}$, em contrapartida Neumann et al. (2007), relatam que não houve efeito da altura de corte nos valores médios de proteína bruta, em experimento avaliando diferentes alturas de colheita em plantas de milho.

Quanto às épocas de semeadura verificou-se que as realizadas em 30/out e 15/nov foram as responsáveis pelos maiores acúmulos de proteína bruta, com rendimentos de 1.280 e $1.288 \mathrm{~kg} \mathrm{ha}^{-1}$, superando as demais, fato este corroborado por Rezende et al. (2005).

Outro ponto importante a considerar refere-se ao aspecto significativo do consórcio vs. monocultivo. Nesse contexto verifica-se que o consórcio apresentou rendimento de $1.064 \mathrm{~kg} \mathrm{ha}^{-1}$ superando o monocultivo $\left(762 \mathrm{~kg} \mathrm{ha}^{-1}\right)$. Pode-se observar que independe do sistema de corte empregado o valor do rendimento de proteína bruta (sorgo+soja) superou o monocultivo do sorgo em 413, 268 e $225 \mathrm{~kg} \mathrm{ha}^{-1}$ em relação aos sistemas 1, 2 e 3, respectivamente (TAB. 4).

Com base nos resultados observados nesse trabalho, pode-se destacar a importância do consórcio com leguminosa, principalmente na adição de proteína à forragem de gramíneas, melhorando seu valor nutritivo. Resultados semelhantes de acréscimos no rendimento de proteína bruta total nos sistemas consorciados também foram observados em outros trabalhos (REZENDE et al., 2000; REZENDE et al., 2005; SILVA et al., 2003; SILVA et al., 2004).

\section{Conclusões}

1. As épocas de semeadura alteraram significativamente o rendimento forrageiro e o teor de proteína bruta do material consorciado, observando-se rendimentos crescentes dessas características com a precocidade da semeadura;

2. As cultivares de soja não alteraram o rendimento forrageiro do consórcio;

3. O sistema de corte 1 (rente ao solo) proporcionou os maiores rendimentos de massa verde, matéria seca e proteína bruta dos materiais consorciados;

4. O sistema de consórcio sorgo-soja proporcionou maior rendimento de massa verde, matéria seca e proteína bruta, comparado ao monocultivo de sorgo.

\section{Agradecimento}

À FAPEMIG (Fundação de Amparo à Pesquisa do Estado de Minas Gerais), que promove atividades de fomento, apoio e incentivo a pesquisas científicas e tecnológicas em Minas Gerais, possibilitando a realização do estudo através do fornecimento de auxílio financeiro.

\section{Referências}

ASSOCIATION OF OFFICIAL AGRICULTURAL CHEMISTS (AOAC). Official methods of analisys. 15. ed. Virginia: AOAC, 1990. 684 p. v. 1.

AZEVEDO, D. M. P. et al. Atributos físicos e químicos de um Latossolo Amarelo e distribuição do sistema radicular da soja sob diferentes sistemas de preparo no cerrado maranhense. Revista Ciência Agronômica, v. 38, n. 01, p. 32-40, 2007.

BARROS, H. B. et al. Efeito das épocas de semeadura no comportamento de cultivares de soja, no sul do estado do Tocantins. Revista Ceres, v. 50, n. 291, p. 565-572, 2003.

BEZERRA, A. P. A. et al. Rendimento, componentes da produção e uso eficiente da terra nos consórcios sorgo $\mathrm{x}$ feijãode-corda e sorgo x milho. Revista Ciência Agronômica, v. 38, n. 01, p. 104-108, 2007.

BOTREL, E. P.; REZENDE, P. M. de. Maximização da exploração da soja. XV. Efeito de cultivares e épocas de adubação nitrogenada na produção de feno e grãos de rebrota. Revista Ciência e Agrotecnologia, v. 23, n. 01, p. 118-123, 1999.

CORTE, E. et al. Consórcio sorgo-soja. VII. Sistemas de corte no rendimento forrageiro das culturas consorciadas. Ciência e Agrotecnologia, Lavras, v. 27, n. 03, p. 681-688, 2003.

EVANGELISTA, A. R. et al. Composição bromatológica de silagem de sorgo (sorghum bicolor (L.) MOENCH) aditivadas com forragem de leucena (Leucaena leucocephala (LAM.) Dewit). Ciência e Agrotecnologia, v. 29, n. 02, p. 429-435, 2005.

FERREIRA, D. F. SISVAR: um programa para análises e ensino de estatística. Revista Symposium, v. 06, p. 36-41, 2008.

GHOSH, P. K. et al. Assessment of nutrient competition and nutrient requirement in soybean/sorghum intercropping system. European Journal of Agronomy, v. 31, n. 01, p. 43-50, 2009.

GHOSH, P. K. et al. Comparative effectiveness of cattle manure, poultry manure, phosphocompost and fertilizerNPK on three cropping systems in vertisols of semi-arid tropics. I. Crop yields and system performance. Bioresource Technology, v. 95, p. 77-83, 2004.

GRIS, C. F. et al. Épocas de corte e cultivares na composição mineral de feno de soja [Glycine max (L.) Merrill]. Ciência e Agrotecnologia, v. 32, n. 02, p. 413-419, 2008.

GUARESCHI, R. F. et al. Produção de biomassa de milho silagem em função do arranjo populacional e adubação. Revista Ciência Agronômica, v. 39, n. 03, p. 468-475, 2008. 
NEUMANN, M. et al. Características da fermentação da silagem obtida em diferentes tipos de silo sob efeito do tamanho de partícula e da altura de colheita das plantas de milho. Ciência Rural, v. 37, n. 03, p. 847-854, 2007.

PEDÓ, L. F. B. et al. Fracionamento dos carboidratos de silagens de milho safrinha colhidas em diferentes alturas de corte. Ciência Rural, v. 39, n. 01, p. 188-194, 2008.

PINHO, R. G. V. et al. Produtividade e qualidade da silagem de milho e sorgo em função da época de semeadura. Bragantia, v. 66, n. 02, p. 235-245, 2007.

REZENDE, M. R. et al. Consórcio sorgo-soja XII. Produção de forragem de cultivares de soja e híbridos de sorgo consorciados na entrelinha, em dois sistemas de corte. Revista Ceres, v. 52, n. 299 , p. $59-71,2005$.

REZENDE, P. M. de; BLANK, A. F.; RESENDE, G. M. Maximização da exploração da soja [Glycine max ( L.) Merrill]. XII. Efeito de sistemas de corte e cultivares na produção de feno. Ensaios e Ciência, v. 01, n. 01, p. 131-141, 1997.

REZENDE, P. M. de et al. Consórcio sorgo-soja. VIII. Sistemas de corte, cultivares de soja e híbridos de sorgo na produção de forragem das culturas consorciadas na entrelinha e monocultivo de sorgo. Revista Brasileira de Agrociência, v. 10, n. 04, p. 475-481, 2004.

REZENDE, P. M. de et al. Consórcio sorgo-soja. IV. Estudo comparativo em função da rebrota de cultivares de sorgo e soja consorciados na entrelinha e em monocultivo no rendimento de forragem. Ciência e Agrotecnologia, v. 24, p. 215-223, 2000. Edição Especial.
RIBEIRO, A. C.; GUIMARÃES, P. G.; VICENTE, V. H. A. Recomendações para o uso de corretivos e fertilizantes em Minas Gerais. 5a Aproximação. Lavras: SBCS, 1999. 359 p.

RODRIGUES FILHO, O. et al. Produção e composição bromatológica de quatro híbridos de sorgo forrageiro [Sorghum bicolor (L.) Moench] submetidos a três doses de nitrogênio. Ciência Animal Brasileira, v. 07, n. 01, p. 37-48, 2006.

SANTOS, J. P. et al. Consórcio sorgo-soja XIII: Efeito de sistemas de corte e arranjo de plantas no desempenho forrageiro do sorgo. Ciência e Agrotecnologia, v. 33, n. 02 p. 397-404, 2009.

SILVA A. G. de et al. Consórcio sorgo-soja. I. Produção de forragem de cultivares de soja e híbridos de sorgo, consorciadas na linha, em dois sistemas de corte. Ciência Rural, v. 30, n. 06, p. 933-939, 2000

SILVA, A. G. et al. Consórcio sorgo-soja. XI. Rendimento de forragem de cultivares de soja e híbridos de sorgo, consorciadas na linha, em diferentes cortes. Revista Ensaio e Ciência, v. 08, n. 02, p. 125-138, 2004.

SILVA, A. G. et al. Consórcio sorgo-soja. IX. Influencia de sistemas de cortes, na produção de forragem de sorgo e soja consorciados na linha e do sorgo em monocultivo. Ciência e Agrotecnologia, v. 27, n. 02, p. 451-461, 2003.

YASSIN, N.; MORAIS, A. R. de; MUNIZ, J. A. Análise de variância em um experimento fatorial de dois fatores com tratamentos adicionais. Ciência e Agrotecnologia, v. 26, p. 1541-1547, 2002. Edição Especial. 